\title{
Testing the effectiveness of a self-efficacy based exercise intervention for inactive people with type 2 diabetes mellitus: design of a controlled clinical trial
}

\author{
Marion MP van der Heijden ${ }^{1}$, François Pouwer ${ }^{1 *}$, Arnold C Romeijnders ${ }^{2}$ and Victor JM Pop ${ }^{1}$
}

\begin{abstract}
Background: Sufficient exercise is important for people with Type 2 Diabetes Mellitus (T2DM), as it can prevent future health problems. Despite, it is estimated that only $30-40 \%$ of people with T2DM are sufficiently active. One of the psychosocial constructs that is believed to influence physical activity behaviour, is exercise self-efficacy. The goal of this study is to evaluate a patient-tailored exercise intervention for people with T2DM that takes exercise self-efficacy into account.
\end{abstract}

Methods/Design: This study is conducted as a non-randomized controlled clinical trial. Patients are eligible when they are diagnosed with T2DM, exercise less than advised in the ADA guideline of $150 \mathrm{~min} /$ week of moderate-intensity aerobic physical activity, have an BMI $>25$ and are between 18 and 80 years old. Recruitment takes place at a Primary care organization of general practitioners and practice nurses in the south of the Netherlands.

Participants are allocated to three groups: An advice intervention -for participants with a high exercise self-efficacy score- in which participants receive a patient-tailored exercise intervention, an intensive intervention -for participants with a low exercise self-efficacy score- in which participants receive a patient-tailored exercise intervention accomplished by a group based intervention, and a control group in which participants receive regular Dutch diabetes care. The primary outcome measure of this study is physical activity. Secondary outcome measures are health status, (symptoms of) depression, exercise self-efficacy, Body Mass Index (BMI), blood pressure and glycemic control.

Discussion: We aimed to design an intervention that can be implemented in Primary care, but also to design an easy accessible program. This study is innovative as it is -to our best knowledge- the first study that takes level of exercise self-efficacy of people with T2DM into account by means of giving extra support to those with the lowest exercise self-efficacy. If the program succeeds in increasing the amount of physical activity it can be implemented in regular primary care.

Trial registration: Dutch Trial Register NTR2734

\footnotetext{
* Correspondence: F.Pouwer@uvt.nl

'Department of Medical Psychology and Neuropsychology, Center of

Research on Psychology in Somatic diseases (CoRPS), Tilburg University,

Tilburg, the Netherlands

Full list of author information is available at the end of the article
} 


\section{Background}

Diabetes mellitus is a chronic, metabolic disorder characterized by hyperglycemia as a result of a defect in insulin secretion and/or insulin resistance [1]. In 2000 the worldwide prevalence of diabetes mellitus was 171 million. This is expected to increase up to 366 million in 2030 [2]. Approximately $90 \%$ of the people with diabetes mellitus have type 2 diabetes mellitus (T2DM) [3].

T2DM often results in (severe) micro- and macrovascular complications, such as cardiovascular problems, retinopathy, neuropathy and kidney failure [1]. Approximately $72 \%$ of the people with T2DM have at least one of these complications [4]. Besides the burden for the patient, this also imposes a burden on the health care system: people with one or more micro- and/or macro vascular T2DM complication(s) cost $70-350 \%$ as much a year compared to patients without T2DM complications [4]. In addition, global mortality attributable to diabetes was estimated to be 2.9 million people in 2000, 5.2\% of all deaths [5].

Physical inactivity is one of the major risk factors for T2DM and related complications, independent of body mass index (BMI) [6-8]. Increasing physical activity reduces the risk for T2DM and its complications by enhancing metabolic control. Moreover, appropriate levels of physical activity are associated with increased cardiorespiratory fitness, increased health related quality of life and a reduced risk of total- and cardiovascular mortality [9-11]. The American Diabetes Association advises people with T2DM to have at least $150 \mathrm{~min} /$ week of moderateintensity aerobic physical activity (50-70\% of maximum heart rate) to maximize the effects of physical activity. In addition, resistance training should be performed three times per week in the absence of contraindications [12].

Because of its beneficial effects, achieving and/or maintaining an appropriate level of exercise is an important goal in diabetes management [12]. Despite, it is estimated that only $30-40 \%$ of people with T2DM are sufficiently active $[13,14]$. This percentage appeared to be stable in recent decades [15] and is significantly lower compared to people without T2DM [13,16]. Physical activity levels might be increased by means of an exercise intervention. Several intervention elements are thought to increase the success rate of such an intervention. To start with, an exercise intervention should imply more than just education [17]. In addition, a patient-tailored exercise plan optimises the effect of the intervention and can increase adherence to the exercise routine $[18,19]$. A gradual increase of physical activity [19] can avoid injuries. Also, the use of multiple behavioural components such as goal-setting, problem solving and feedback can further increase the (long-term) success of the intervention [20]. In addition, the American College of Sports Medicine and the American Diabetes Association advised in their 2010 joint statement on Exercise \& Diabetes to focus exercise interventions on self-efficacy [10].
Self-efficacy is derived from the Social Cognitive Theory, which states that a behavioural change is made possible by a personal sense of control. Self-efficacy is one of the main constructs of this theory and is the "belief in one's capabilities to organize and execute the courses of action required to produce given attainments" [21]. Self-efficacy for exercise/physical activity (exercise self-efficacy) is believed to influence physical activity behaviour [22-24]. In people with T2DM a high level of exercise self-efficacy is thought to be predictive of exercise initiation and maintenance over time [25], and is thought to mediate the relationship between an exercise intervention and physical activity [26]. Also, an increased level of exercise selfefficacy makes it more likely that participants indeed use strategies to improve their physical activity levels [27].

A patient-tailored exercise intervention with a gradual increase of physical activity and multiple components such as goals setting, has the potential to increase the physical activity level of people with T2DM. This can be provided by means of several individual physiotherapy consultations in which a patient tailored exercise plan is provided and progression evaluated. Because of its important predictive and mediating role, exercise self-efficacy has the potential to discriminate between subjects who can be helped with such individual physiotherapy consultations, and those who are in need of extra support because of their low exercise self-efficacy. Extra support can be given by providing an additional group-based program. A group-based program gives room to verbal persuasion by the physiotherapist and/or group members and vicarious experiences which are sources of self-efficacy [28] and can therefore increase the level of exercise self-efficacy.

\section{Objectives and hypotheses}

The goal of this study is to evaluate a patient-tailored exercise program for people with T2DM that takes levels of exercise self-efficacy into account. If the program succeeds in increasing the amount of physical activity it can be implemented in regular Primary diabetes care.

The primary outcome measure of this study is physical activity. We hypothesize that the intervention will significantly increase the level of physical activity in the intervention groups compared to the control group. In addition, we will examine which determinants contribute to a successful change of the amount of physical activity. Most literature seems to agree that a high age $[15,16,22,29,30]$, low education $[15,22,30]$ and being female $[16,22,30]$, are associated with a lower level of physical activity. Although a higher BMI seems to correlate with physical activity among adults [22], the results of studies on people with T2DM are conflicting [13,15,29]. In addition a low exercise self-efficacy [22], low social support [22], a depressed mood [31] and a type D personality [32] are thought be determinants of a low level of physical activity. We 
therefore hypothesize that a young age, high education, being male, low BMI, a high level of exercise self-efficacy, a high level social support, the absence of a depressed mood and not having a type $\mathrm{D}$ personality contribute to a successful change of the level of physical activity.

Secondary outcome measures are health status, (symptoms of) depression, exercise self-efficacy, BMI, blood pressure and glycemic control.

In line with the Look AHEAD trial [33] and the DARE study [34] we hypothesize that our intervention will significantly improve the physical component of health status but not the mental component-, compared to the control group.

In two systematic reviews $[35,36]$ on the effects of physical activity on depressive symptoms in elderly people, it was found that increased levels of exercise can lower depression rates and reduce depressive symptoms in the short term. In accordance, we therefore hypothesize that the intervention of the current study will significantly reduce depressive symptoms, compared to the control group.

The intervention is thought to provide participants personal mastery experiences which is a source of self-efficacy [28]. We therefore hypothesize that the intervention will significantly increase exercise self-efficacy, compared to the control group. We additionally hypothesize that the change of exercise self-efficacy will be larger in those with low exercise self-efficacy at baseline as they will receive additional support.

Glycemic control is assessed by means of haemoglobin $A_{1 C}$. As physical activity is thought to improve glycemic control [37-39] we hypothesize that our intervention will significantly reduce haemoglobin $\mathrm{A}_{1 \mathrm{C}}$, compared to the control group.

Based on literature, an effect of increased physical activity on body mass or BMI can not be expected [37,38]. We therefore hypothesize that the intervention will not lead to significant decrease in BMI, compared to the control group.

Literature on the effect of physical activity on blood pressure is somewhat ambiguous. In the review of Thomas et al. [37] no effect on diastolic of systolic blood pressure was found. The American College of Sports Medicine and American Diabetes Association concluded in their joint statement on Exercise and Diabetes that only slight reductions of systolic blood pressure can be expected [10]. However, in a meta-analysis by Snowling et al. [40] small to moderate effects of aerobic or a combination of aerobic and resistance exercise on blood pressure were found. We therefore hypothesize that the intervention of the current study will significantly reduce systolic blood pressure in those with an elevated blood pressure, compared to the control group.

Finally, diabetes self-efficacy and quality of sleep are explorative outcome measures. We therefore have no hypotheses regarding these outcome measures.

\section{Methods/Design}

\section{Study design}

This study is conducted as a non-randomized controlled clinical trial. Participants are allocated to three groups: An advice intervention in which participants receive a patient-tailored exercise intervention, an intensive intervention in which participants receive a patient-tailored exercise intervention accomplished by a group based intervention, and a control group in which participants receive regular Dutch diabetes care.

\section{Eligibility}

Patients are eligible when they are diagnosed with T2DM, exercise less than advised in the ADA guideline of $150 \mathrm{~min} /$ week of moderate-intensity aerobic physical activity [12], have an BMI $>25$ and are between 18 and 80 years old.

Patients are excluded when they recently participated in an exercise program on an indication other than diabetes or suffer from a serious diabetes complication or other disabling co-morbidity (e.g. unstable angina pectoris, heart failure, extremely high blood pressure (systolic $>200$, diastolic $>120$ ), cerebrovascular accident, serious neuropathy, kidney failure, diabetic foot ulcer(s), proliferative retinopathy, a serious form of cancer, orthopaedic constraints, serious exertion hypertension, unstable coronary ischemia). Patients with silent myocardal ischemia are also excluded. Silent myocardial ischemia is defined as an objective documentation of myocardial ischemia in the absence of angina or angina equivalents [41]. The prevalence of silent myocardial ischemia varies from $9 \%$ up to $57 \%$ in people with T2DM [42], and can be verified by a electrocardiogram exercise stress test.

\section{Recruitment}

Participants are recruited in rural areas surrounding the city of Eindhoven, the Netherlands. Recruitment takes place at a primary care organization of general practitioners and practice nurses in the south of the Netherlands, PoZoB (Praktijkondersteuning Zuid-oost Brabant). Eligibility is checked by the general practitioner and/or the practice nurse.

\section{Allocation procedure}

For practical reasons, seven areas are pointed out as 'intervention area'. People outside these areas are invited for the control group.

Participants of the intervention are allocated to the intensive intervention or the advice intervention after filling out the baseline questionnaire. Allocation is based on their score on the Exercise Self-efficacy Scale (ESS) that has been developed by Bandura [43]. Since there is to the best of our knowledge no other study that uses the ESS to discriminate between people with T2DM in a 
exercise intervention, we use the median score on the ESS to split the group of intervention participants approximately in two equal halves: Participants with a score between 0 and 40 are allocated in the intensive intervention. Participants with a score between 41 and 100 are allocated to the advice intervention.

\section{Intervention}

The interventions' duration is 36 weeks, with a follow-up period of one year.

In the advice intervention (for participants with a high exercise self-efficacy), the intervention starts with an intake consultation with a physiotherapist. During this intake, information about the intervention and 'Diabetes and exercise' is provided. Next, the current physical condition in terms of aerobic power, muscle strength, blood pressure, BMI and waist-circumference is established. Exercise tolerance is assessed with the six minute walk test [44]. The test is suitable for elderly [45] and a proper reflection of activities of daily living [46]. Muscle strength is assessed with one repetition maximum tests for the abdominal, back, arm and leg muscles. One repetition maximum tests are a widely spread and valid way to asses muscle strength in vivo [47]. In addition, the goals and the exercise preferences of the participant are discussed. Subsequently, a patient-tailored exercise plan is drafted. The exercise plan consists of a combination of aerobic and resistance exercise, replenished by balance and flexibility drills, with the aim of exercising three hours a week, with a gradual increase of intensity, difficulty and duration. When applicable, at-home drills are taught. An information folder with the exercise plan, written prescription of the drills, an exercise journal and information on 'diabetes and exercise' are provided. Also, an information session with a dietician is scheduled, in order to provide information on nutrition, diabetes and exercise.

In consultations after 4, 12, 24 and 36 weeks, progression is assessed and the exercise plan is evaluated. Also, feedback is given and possible barriers to exercise and their conceivable solutions are discussed. If necessary, the exercise plan can be adapted. In the consultations after 24 and 36 weeks, additionally, relapse prevention and the continuation of exercise after the intervention are discussed.

Participants of the intensive intervention (for participants with a low exercise self-efficacy) receive a similar intervention as do participants of the advice intervention, but in addition they receive physiotherapist guided group training. Groups consist of eighth participants maximally. The 24 group trainings contain aerobic, resistance, balance, and flexibility drills. From week one up to week eight there are two group sessions of one hour a week. From week nine up to week sixteen there is one group session a week. During these sixteen weeks, the participant is expected to exercise home-based to meet up the requirements of their exercise plan. After, participants are expected to follow up their exercise plan home-based.

\section{Data collection}

The assessments of the self-reported data take place at baseline, at 36 weeks, at 1 year and at 1 year and 36 weeks. The intervention participants receive two additional questionnaires at 12 weeks, and 24 weeks. Questionnaires will be sent out by post, along with a stamped ballot paper envelope.

Biomedical parameters BMI, blood pressure and haemoglobin $\mathrm{A}_{1 \mathrm{C}}$ are assessed as part of regular care up to four times a year. In addition, intervention participants will receive a BMI and blood pressure assessment at baseline, at 12 weeks, at 24 weeks, and at 36 weeks during their physiotherapy consultations (Table 1).

\section{Outcome parameters}

Primary outcome measure

Physical activity The level of physical activity is assessed by means of self-report using the Short QUestionnaire to ASsess Health enhancing physical activity (SQUASH). This questionnaire has been proved to be a reliable and valid measurement in adults [48]. Participants are asked to

Table 1 Measurements and time points

\begin{tabular}{|c|c|}
\hline Intervention group & Control group \\
\hline
\end{tabular}

\section{Concept (questionnaire)}

Demographic variables $\quad x$

Physical activity (SQUASH) $x \times x \quad x \quad x \quad x \quad x \quad x \quad x$

Health Status (SF12) $\quad x \quad x \quad x \quad x \quad x \quad x \quad x \quad x \quad x \quad x$

Depressive symptoms $x \quad x \quad x \quad x \quad x \quad x \quad x$ (PHQ9)

Exercise self-efficacy (ESS) $x \quad x \quad x \quad x \quad x \quad x \quad x \quad x \quad x \quad x$

Social support

Type D (DS14)

Diabetes self-efficacy

Quality of sleep

Patient satisfaction

\begin{tabular}{|c|c|c|c|c|c|c|c|c|c|}
\hline$x$ & & & & & & $x$ & & & \\
\hline$x$ & & & & & & $x$ & & & \\
\hline$x$ & $x$ & $x$ & $x$ & $x$ & $x$ & $x$ & $x$ & $x$ & $\gamma$ \\
\hline$X$ & $x$ & $x$ & $x$ & $x$ & $x$ & $x$ & $x$ & $x$ & $\gamma$ \\
\hline
\end{tabular}

Clinical measurements

BMI

$x \quad x \quad x \quad$ Part of regular diabetes care*

Bloodpressure

$x \times x$

Part of regular diabetes care*

Glycemic control Part of regular Part of regular (hemoglobin $\mathrm{A}_{1 \mathrm{C}}$ ) diabetes care diabetes care*

To - baseline; T1 - after 12 weeks; T2 - after 24 weeks; T3 - after 36 weeks (end of intervention); T4 - after 1 year (post intervention); T5 - after 1 year and 36 weeks (post intervention); SQUASH - Short QUestionnaire to ASsess Health enhancing physical activity; SF12 - Short Form Health Survey 12;

PHQ9 - Patient Health Questionnaire 9; ESS - Exercise self-efficacy scale; DS14 - Type D Scale-14; * up to 4 times a year. 
indicate their level of physical activity during an average week in the past month, with regard to activity at work (if applicable), commuting activities (if applicable), household activities (if applicable), and leisure time. The frequency of activities (days/week), as well as the duration (average time/day) and experienced intensity of these activities (light, moderate, vigorous), are measured. Each activity is represented by a metabolic equivalent (MET). MET expresses the cost of energy from physical activities as multiples of the resting metabolic rate. Activities can be divided into three categories of intensity based on their MET: light ( 2 to $<4.0 \mathrm{METs})$, moderate $(4.0$ to $<6.5$ METs) and vigorous ( $\geq 6.5 \mathrm{METs}$ ) intensity [48].

\section{Secondary outcome measures}

Health status Health status is assessed using the Short Form Health Survey 12 (SF12), a shortened version of the Short Form Health Survey 36 [49]. The SF12 is a self-reported questionnaire and consists of twelve items with two component summary scores: physical health (PCS) and mental health (MCS). Both components are scored on a scale from 0 to 100 , with a higher score representing a better health status [50].

Depressive symptoms Depressive symptoms are assessed with the self-reported Patient Health Questionnaire 9 (PHQ9). The questionnaire contains nine items derived from the Diagnostic and Statistical Manual of Mental Disorders, Fourth Edition (DSM-IV), related to the past two weeks. The items are scored on a four point scale, ranging from 0 (not at all) to 3 (almost every day) [51].

Exercise self-efficacy Exercise self-efficacy is assessed with the ESS [43]. This self-reported questionnaire contains eighteen items that describe situations during which it could be difficult to adhere to an exercise routine, for example: "when I am feeling tired" or "during bad weather". Participants are asked to rate their degree of confidence to continue with regular exercise in the listed situations. The ESS uses a 100-point scale for each item, ranging from 0 ("I cannot do this at all") to 100 ("I am certain that I can do it"), the higher scores reflecting higher levels of exercise self-efficacy. The total ESS score is calculated as the mean of all the items. The ESS appeared to have a single factor solution $[52,53]$. The questionnaire is positively correlated with the frequency of exercise [52], has no floor or ceiling effects, good internal consistency with an Cronbachs $\alpha$ coefficient of 0,95 and has good responsiveness to change [53].

Since a relatively high percentage of people with T2DM are retired, the original item "When I am feeling under pressure from work" is in the current study adapted to "When I am feeling under pressure".

$\mathrm{BMI}$, blood pressure and hemoglobin $\mathrm{A}_{1 \mathrm{C}}$ Biomedical parameters (laboratory tests and physical examination) are assessed as part of regular care up to four times a year and performed by the Diagnostic Centre in (areas surrounding the city of) Eindhoven, the Netherlands. To assess glycemic control we retrieve data from their files on haemoglobin $\mathrm{A}_{1 \mathrm{C}}$. In addition, data on BMI and blood pressure (systolic and diastolic) are retrieved from the files. Participants of the intervention receive additional BMI and blood pressure measurements as part of the physiotherapist consultations.

\section{Explorative outcome measures}

Diabetes self-efficacy Twelve self-reported items are used to quantify diabetes self-efficacy. The participants are asked to rate their level of confidence to execute diabetes self-care behaviours. The items are scored on a sixpoint likert scale, from 0 ('totally disagree') to 5 ('totally agree') and concern 'prevention of high blood sugars', 'healthy diet,' 'avoid/reduce obesity', 'proper use of medication,' 'enough exercise,' 'no smoking,' 'no alcohol,' 'ask for help when necessary', 'follow up appointments with caregivers', 'follow up life-style advice in special situations', ask for clarification regarding T2DM when things are unclear' and 'accepting T2DM'.

Quality of sleep Thirteen self-reported items assess various aspects of quality of sleep, related to the past week. The items concern the length of sleep, difficulty of getting to sleep or staying a sleep, overall quality of sleep, resting during the day, sleeping during the day, difficulty staying awake during the day and sleep-related medications.

\section{Additional measures}

Demographic and clinical variables Age, gender, nationality, marital status, living arrangements, education, work situation, smoking behaviour, alcohol behaviour and year of diabetes diagnosis are assessed by means of a self-reported questionnaire at baseline. Co-morbidities, medication and diabetes treatment (diet and/or tablets and/or insulin) are retrieved from (electronic) medical records when possible.

Social support Social support not only has a main effect on the level of physical activity, a study with older adults with multiple illnesses showed that social support also has a synergistic effect with exercise self-efficacy [54]. Social support is measured by four questions that are rated on a five point scale $(0=$ no support, $4=$ much support $)$.

Type D personality People with a Type D personality have a general tendency towards increased negative affectivity and inhibit these emotions in social situations. People with a type D personality adhere less to the physical activity norm [32].

Type D personality is measured by the Type D Scale14 (DS14). The DS14 comprises fourteen items and is scored on a five point scale $(0=$ false, $4=$ correct $)$. The DS14 consists of two subscales for which sum scores are calculated: negative affectivity and social inhibition. Both scales are internally consistent (Cronbachs $\alpha$ coefficient 
of 0.88 and 0.86 respectively) and are independent of mood and health [55].

Patient satisfaction Participants of the intervention are asked to rate their satisfaction with treatment by means of a self-report questionnaire regarding the organization of the intervention, supervision of the physiotherapist and the content of the intervention. In addition, it is assessed whether the participant intends to continue the level of physical activity after the intervention.

\section{Statistical analyses \\ Sample size and power calculation}

The intervention of this study consists of two groups (an intensive group and an advice group) to which participants are allocated based on their exercise self-efficacy score. Therefore, for analyses, the control group participants will also be allocated to a low exercise self-efficacy control group $($ ESS $\leq 40)$ and a high exercise self-efficacy control group (ESS >40).

Fisher's exact test was used to calculate the number of subjects that have to be included in this study. We expect $50 \%$ of the intervention participants and $25 \%$ of the control group participants to meet up with the requirement of 150 minutes a week of moderate intensity physical activity at the end of the intervention (36 weeks). Taken into account a power of 0.9 , an alpha of 0.05 , an expected drop-out rate of $25 \%$ in the intervention and $50 \%$ in the control group, 94 participants need to be included in the intensive intervention group, 94 participants in the advice intervention group, 142 participants in the high exercise self-efficacy control group, and 142 participants in the low exercise self-efficacy control group. To be able to perform cross-validation and perform analysis in (equally sized) subgroups, an inclusion of 366 participants in the intervention and 586 participants in the control group is desirable.

\section{Planned analyses}

Analyses will be performed using the latest version of the Social Package for Social Sciences (IBM, Chicago, Illinois, USA). Assumptions for parametric analyses will be checked for all analysis, and tests will be performed with a significance level of 5\%. Differences in patient characteristics between groups will be checked be means of T-tests and $\mathrm{X}^{2}$ tests, or there non-parametric equivalents.

Repeated measures analysis of variance and multilevel analysis for longitudinal data will be used to examine longitudinal differences between groups on primary and secondary outcome measures. To test which determinants contribute to a successful change in the level of physical activity, linear/logistic regression analyses will be used. Participants will be analysed within the group to which they were allocated.

\section{Ethical principles}

The study protocol has been approved by the medical ethical committee of the St. Elisabeth Hospital, Tilburg, the Netherlands. Written consent will be obtained from all participants.

\section{Discussion}

The number of people with T2DM is rapidly rising up to 366 million in 2030 [56]. As physical activity can among other things- improve glycemic control, people with T2DM are advised to have at least $150 \mathrm{~min} /$ week of moderate-intensity aerobic physical activity [12]. Unfortunately only $30-40 \%$ of people with T2DM are sufficiently active $[13,14]$. An important predictor of exercise initiation and maintenance in people with T2DM, is exercise self-efficacy [25]. We therefore designed a patienttailored intervention that aims to increase the level of physical activity of the participants, in which extra support is given to those with the lowest exercise selfefficacy.

In this study we aim not only to design an intervention that can directly be implemented in primary care, but also to design an easy accessible program. We chose to use a multi-centre approach with seven physiotherapist practices, so that participants' travelling time is minimized. This approach also allows participants to meet other participants from the neighbourhood, which might stimulate the continuation of exercise after the intervention. Also, the physical condition and preferences of the participants are taken into account in the patient-tailored exercise plan. As a result the exercise plan is suitable for the participant, the risk of injuries is minimized, and adherence might be increased.

This study has several strengths. First, this study is innovative as it is -to the best of our knowledge- the first study that takes levels of exercise self-efficacy of people with T2DM into account, giving extra support to those with the lowest exercise self-efficacy. Secondly, the large number of participants that will be included. As the intervention is embedded in regular diabetes care, we are confident that we will be able to include the required number of participants. Thirdly, as a large portion of the studies on physical activity in people with T2DM focuses on clinical outcomes, we also included psychosocial outcomes such as perceived health status and depressive symptoms. Finally, this study focuses on primary care patients. Primary care patients tend to have less severe co-morbidities compared to secondary care patients, so prevention of future co-morbidities might be possible.

Several limitations of the design of this study also need to be addressed. This study is not randomised. This may lower the validity of our findings. However, by using a matched control group (age and gender) and correcting for baseline differences, we will try to minimize the 
shortcoming of a non-randomised study. Another limitation is the determination of the ESS cut-off point for participant allocation, as it is based on a median score. It is possible that post hoc analysis might suggest that other cut-off points should have been used. Also, glycemic control will be measured only as part of regular diabetes care, as are BMI and blood pressure for the control group participants. As a consequence, the measurement time points of the questionnaires may not correspond with these laboratory assessments. However, BMI and haemoglobin $\mathrm{A}_{1 \mathrm{C}}$ are rather stable biological markers of T2DM and we aimed to design an easy accessible intervention, which includes minimization of the participants' burden. Finally, for practical reasons the measurement of physical activity is by means of self-report. Self-reported physical activity tends to result in an overestimation of levels of activity and different activity patterns compared to more objective estimates [57]. Yet, the SQUASH shows moderate correlations with data from accelerometer measurements [48].

\section{Conclusion}

In conclusion, the need to increase the level of physical activity in people with T2DM is evident, in which exercise self-efficacy can play an important role. In the present study we will evaluate a patient-tailored exercise program for people with T2DM that takes levels of exercise self-efficacy into account.

\section{Competing interests}

The authors declare that they have no competing interests.

\section{Acknowledgements}

This study was financially supported by CZ Health Insurance. We thank PoZoB for their participation.

\section{Author details}

${ }^{1}$ Department of Medical Psychology and Neuropsychology, Center of Research on Psychology in Somatic diseases (CORPS), Tilburg University, Tilburg, the Netherlands. ${ }^{2} \mathrm{PoZ} o \mathrm{~B}$, Coordination Centre of Practice Nurses for South East Netherlands, Veldhoven, the Netherlands.

\section{Authors' contributions}

All authors contributed to the design of the study. VP is the principal investigator of the study. MH drafted the manuscript. FP, AR and VP reviewed/edited the manuscript. All authors approved the various versions including the final version of the manuscript.

Received: 16 March 2012 Accepted: 4 May 2012

Published: 4 May 2012

\section{References}

1. Alberti KG, Zimmet PZ: Definition, diagnosis and classification of diabetes mellitus and its complications. Part 1: diagnosis and classification of diabetes mellitus provisional report of a WHO consultation. Diabet Med 1998, 15(7):539-553

2. Wild S, Roglic G, Green A, Sicree R, King H: Global prevalence of diabetes: estimates for the year 2000 and projections for 2030. Diabetes Care 2004 27(5):1047-1053.

3. Fact sheet No 312 Diabetes http://www.who.int/mediacentre/factsheets/ fs312/en/.

4. Williams R, Van Gaal L, Lucioni C: Assessing the impact of complications on the costs of Type II diabetes. Diabetologia 2002, 45(7):S13-S17.
5. Roglic G, Unwin N, Bennett PH, Mathers C, Tuomilehto J, Nag S, Connolly V, King $\mathrm{H}$ : The burden of mortality attributable to diabetes: realistic estimates for the year 2000. Diabetes Care 2005, 28(9):2130-2135.

6. Hu FB, Manson JE, Stampfer MJ, Colditz G, Liu S, Solomon CG, Willett WC: Diet, lifestyle, and the risk of type 2 diabetes mellitus in women. $N$ Engl J Med 2001, 345(11):790-797.

7. Hu G, Lindstrom J, Valle $\Pi$, Eriksson JG, Jousilahti P, Silventoinen K, Qiao Q, Tuomilehto J: Physical activity, body mass index, and risk of type 2 diabetes in patients with normal or impaired glucose regulation. Arch Intern Med 2004, 164(8):892-896.

8. Sullivan PW, Morrato EH, Ghushchyan V, Wyatt HR, Hill JO: Obesity, inactivity, and the prevalence of diabetes and diabetes-related cardiovascular comorbidities in the U.S., 2000-2002. Diabetes Care 2005, 28(7):1599-1603.

9. Marwick TH, Hordern MD, Miller T, Chyun DA, Bertoni AG, Blumenthal RS Philippides G, Rocchini A: Exercise training for type 2 diabetes mellitus: impact on cardiovascular risk: a scientific statement from the American Heart Association. Circulation 2009, 119(25):3244-3262.

10. American College of Sports Medicine and the American Diabetes Association: Exercise and type 2 diabetes: American College of Sports Medicine and the American Diabetes Association: joint position statement. Med Sci Sports Exerc 2010, 42(12):2282-2303.

11. Hu G, Jousilahti P, Barengo NC, Qiao Q, Lakka TA, Tuomilehto J: Physical activity, cardiovascular risk factors, and mortality among Finnish adults with diabetes. Diabetes Care 2005, 28(4):799-805.

12. Association AD: Standards of medical care in diabetes-2011. Diabetes Care 2011, 34(Suppl 1):S11-S61.

13. Morrato EH, Hill JO, Wyatt HR, Ghushchyan V, Sullivan PW: Physical activity in U.S. adults with diabetes and at risk for developing diabetes, 2003. Diabetes Care 2007, 30(2):203-209.

14. Plotnikoff RC, Johnson ST, Loucaides CA, Bauman AE, Karunamuni ND, Pickering MA: Population-based estimates of physical activity for adults with type 2 diabetes: a cautionary tale of potential confounding by weight status. J Obes 2011, 2011. doi: 10.1155/2011/561432.

15. Zhao G, Ford ES, Li C, Mokdad AH: Compliance with physical activity recommendations in US adults with diabetes. Diabet Med 2008, 25(2):221-227.

16. Zhao G, Ford ES, Li C, Balluz LS: Physical activity in u.s. Older adults with diabetes mellitus: prevalence and correlates of meeting physical activity recommendations. J Am Geriatr Soc 2011, 59(1):132-137.

17. Marcus BH, Williams DM, Dubbert PM, Sallis JF, King AC, Yancey AK, Franklin BA, Buchner D, Daniels SR, Claytor RP: Physical activity intervention studies: what we know and what we need to know: a scientific statement from the American Heart Association Council on Nutrition, Physical Activity, and Metabolism (Subcommittee on Physical Activity); Council on Cardiovascular Disease in the Young; and the Interdisciplinary Working Group on Quality of Care and Outcomes Research. Circulation 2006, 114(24):2739-2752

18. Kahn EB, Ramsey LT, Brownson RC, Heath GW, Howze EH, Powell KE, Stone EJ, Rajab MW, Corso P: The effectiveness of interventions to increase physical activity. A systematic review. Am J Prev Med 2002, 22(4 Suppl):73-107.

19. Praet SF, van Loon LJ: Optimizing the therapeutic benefits of exercise in Type 2 diabetes. J Appl Physiol 2007, 103(4):1113-1120.

20. Simons-Morton DG, Calfas KJ, Oldenburg B, Burton NW: Effects of interventions in health care settings on physical activity or cardiorespiratory fitness. Am J Prev Med 1998, 15(4):413-430

21. Bandura A: Self-efficacy: the exercise of control. New York: Freeman; 1997.

22. Trost SG, Owen N, Bauman AE, Sallis JF, Brown W: Correlates of adults' participation in physical activity: review and update. Med Sci Sports Exerc 2002, 34(12):1996-2001

23. Delahanty LM, Conroy MB, Nathan DM: Psychological predictors of physical activity in the diabetes prevention program. J Am Diet Assoc 2006, 106(5):698-705.

24. McAuley E, Jerome GJ, Elavsky S, Marquez DX, Ramsey SN: Predicting long-term maintenance of physical activity in older adults. Prev Med 2003, 37(2):110-118.

25. Allen NA: Social cognitive theory in diabetes exercise research: an integrative literature review. Diabetes Educ 2004, 30(5):805-819.

26. Dutton GR, Tan F, Provost BC, Sorenson JL, Allen B, Smith D: Relationship between self-efficacy and physical activity among patients with type 2 diabetes. J Behav Med 2009, 32(3):270-277.

27. Anderson ES, Winett RA, Wojcik JR, Williams DM: Social cognitive mediators of change in a group randomized nutrition and physical activity intervention: social support, self-efficacy, outcome expectations and selfregulation in the guide-to-health trial. J Health Psychol 2010, 15(1):21-32. 
28. Bandura A: Self-efficacy: toward a unifying theory of behavioral change. Psychol Rev 1977, 84(2):191-215.

29. Nelson KM, Reiber G, Boyko EJ: Diet and exercise among adults with type 2 diabetes: findings from the third national health and nutrition examination survey (NHANES III). Diabetes Care 2002, 25(10):1722-1728.

30. Plotnikoff RC, Taylor LM, Wilson PM, Courneya KS, Sigal RJ, Birkett N, Raine K, Svenson LW: Factors associated with physical activity in Canadian adults with diabetes. Med Sci Sports Exerc 2006, 38(8):1526-1534.

31. Lysy Z, Da Costa D, Dasgupta K: The association of physical activity and depression in Type 2 diabetes. Diabet Med 2008, 25(10):1133-1141.

32. Mommersteeg PM, Kupper N, Denollet J: Type D personality is associated with increased metabolic syndrome prevalence and an unhealthy lifestyle in a cross-sectional Dutch community sample. BMC Publ Health 2010, 10:714.

33. Williamson DA, Rejeski J, Lang W, Van Dorsten B, Fabricatore AN, Toledo K: Impact of a weight management program on health-related quality of life in overweight adults with type 2 diabetes. Arch Intern Med 2009, 169 (2):163-171.

34. Reid RD, Tulloch HE, Sigal RJ, Kenny GP, Fortier M, McDonnell L, Wells GA, Boule NG, Phillips P, Coyle D: Effects of aerobic exercise, resistance exercise or both, on patient-reported health status and well-being in type 2 diabetes mellitus: a randomised trial. Diabetologia 2010, 53(4):632-640.

35. Blake H, Mo P, Malik S, Thomas S: How effective are physical activity interventions for alleviating depressive symptoms in older people? A systematic review. Clin Rehabil 2009, 23(10):873-887.

36. Sjosten N, Kivela SL: The effects of physical exercise on depressive symptoms among the aged: a systematic review. Int I Geriatr Psychiatry 2006, 21(5):410-418.

37. Thomas DE, Elliott EJ, Naughton GA: Exercise for type 2 diabetes mellitus. Cochrane Database Syst Rev 2006, 3:CD002968.

38. Boule NG, Haddad E, Kenny GP, Wells GA, Sigal RJ: Effects of exercise on glycemic control and body mass in type 2 diabetes mellitus: a metaanalysis of controlled clinical trials. JAMA 2001, 286(10):1218-1227.

39. Umpierre $D$, Ribeiro $P A B$, Kramer CK: Physical activity advice only or structured exercise training and association with Hba1c levels in type 2 diabetes. A systematic review and meta-analysis. JAMA 2011, 305 (17):1790-1799.

40. Snowling NJ, Hopkins WG: Effects of different modes of exercise training on glucose control and risk factors for complications in type 2 diabetic patients: a meta-analysis. Diabetes Care 2006, 29(11):2518-2527.

41. Cohn PF, Fox KM, Daly C: Silent myocardial ischemia. Circulation 2003, 108 (10):1263-1277.

42. Janand-Delenne B, Savin B, Habib G, Bory M, Vaque P, Lassmann-Vaque V: Silent myocardial ischemia in patients with diabetes: who to screen. Diabetes Care 1999, 22(9):1396-1400.

43. Bandura A: Guide for constructing self-efficacy scales. In Self-efficacy beliefs of adolescents. edn. Edited by Pajares F, Urdan T. Greenwich: Information Age Publishing; 2006:307-337.

44. Butland RJ, Pang J, Gross ER, Woodcock AA, Geddes DM: Two-, six-, and 12minute walking tests in respiratory disease. Br Med J (Clin Res Ed) 1982, 284(6329):1607-1608.

45. Enright PL, McBurnie MA, Bittner $\mathrm{V}$, Tracy RP, McNamara R, Arnold A, Newman AB: The 6-min walk test: a quick measure of functional status in elderly adults. Chest 2003, 123(2):387-398.

46. Solway S, Brooks D, Lacasse Y, Thomas S: A qualitative systematic overview of the measurement properties of functional walk tests used in the cardiorespiratory domain. Chest 2001, 119(1):256-270.

47. Verdijk LB, van Loon L, Meijer K, Savelberg HH: One-repetition maximum strength test represents a valid means to assess leg strength in vivo in humans. J Sports Sci 2009, 27(1):59-68.

48. Wendel-Vos GC, Schuit AJ, Saris WH, Kromhout D: Reproducibility and relative validity of the Short QUestionnaire to ASsess Health-enhancing physical activity. J Clin Epidemiol 2003, 56(12):1163-1169.

49. Wee CC, Davis RB, Hamel MB: Comparing the SF-12 and SF-36 health status questionnaires in patients with and without obesity. Health Qual Life Outcomes 2008, 6:11.

50. Ware J Jr, Kosinski M, Keller SD: A 12-Item Short-Form Health Survey: construction of scales and preliminary tests of reliability and validity. Med Care 1996, 34(3):220-233
51. Spitzer RL, Kroenke K, Williams JB: Validation and utility of a self-report version of PRIME-MD: the PHQ primary care study. Primary Care Evaluation of Mental Disorders. Patient Health Questionnaire. JAMA 1999, 282(18):1737-1744

52. Shin $Y$, Jang H, Pender NJ: Psychometric evaluation of the exercise selfefficacy scale among Korean adults with chronic diseases. Res Nurs Health 2001, 24(1):68-76.

53. Everett B, Salamonson Y, Davidson PM: Bandura's exercise self-efficacy scale: validation in an Australian cardiac rehabilitation setting. Int I Nurs Stud 2009, 46(6):824-829.

54. Warner LM, Ziegelmann JP, Schuz B, Wurm S, Schwarzer R: Synergistic effect of social support and self-efficacy on physical exercise in older adults. J Aging Phys Act 2011, 19(3):249-261.

55. Denollet J: DS14: standard assessment of negative affectivity, social inhibition, and Type D personality. Psychosom Med 2005, 67(1):89-97.

56. WHO: Definition, diagnosis and classification of Diabetes Mellitus and it's complications. In Report of a WHO consultation. Part 1. Geneva: World Health Organisation; 1999:1-59.

57. Hagstromer M, Oja P, Sjostrom M: Physical activity and inactivity in an adult population assessed by accelerometry. Med Sci Sports Exerc 2007, 39 (9):1502-1508.

doi:10.1186/1471-2458-12-331

Cite this article as: van der Heijden et al.: Testing the effectiveness of a self-efficacy based exercise intervention for inactive people with type 2 diabetes mellitus: design of a controlled clinical trial. BMC Public Health 2012 12:331

\section{Submit your next manuscript to BioMed Central and take full advantage of:}

- Convenient online submission

- Thorough peer review

- No space constraints or color figure charges

- Immediate publication on acceptance

- Inclusion in PubMed, CAS, Scopus and Google Scholar

- Research which is freely available for redistribution 